\title{
Deletion of the cruciform binding domain in CBP/I4-3-3 displays reduced origin binding and initiation of DNA replication in budding
} yeast

\author{
Wafaa Yahyaoui ${ }^{1}$, Mario Callejo ${ }^{1}$, Gerald B Price ${ }^{1,2}$ and Maria Zannis- \\ Hadjopoulos*1
}

Address: ${ }^{1}$ McGill Cancer Centre, 3655 Promenade Sir William Osler, Montreal, Quebec H3G 1Y6, Canada and ${ }^{2}$ In memoriam Email: Wafaa Yahyaoui - wafaa.yahyaoui@mcgill.ca; Mario Callejo - mario.callejo@mcgill.ca; Gerald B Price - maria.zannis@mcgill.ca; Maria Zannis-Hadjopoulos* - maria.zannis@mcgill.ca

* Corresponding author

Published: 12 April 2007

BMC Molecular Biology 2007, 8:27 doi:10.1 186/147|-2199-8-27

This article is available from: http://www.biomedcentral.com/I47I-2/99/8/27

(C) 2007 Yahyaoui et al; licensee BioMed Central Ltd.

This is an Open Access article distributed under the terms of the Creative Commons Attribution License (http://creativecommons.org/licenses/by/2.0), which permits unrestricted use, distribution, and reproduction in any medium, provided the original work is properly cited.
Received: 26 September 2006 Accepted: 12 April 2007

\begin{abstract}
Background: Initiation of eukaryotic DNA replication involves many protein-protein and proteinDNA interactions. We have previously shown that 14-3-3 proteins bind cruciform DNA and associate with mammalian and yeast replication origins in a cell cycle dependent manner.

Results: By expressing the human 14-3-3E, as the sole member of 14-3-3 proteins family in


knockout, conserves its cruciform binding activity, and associates in vivo with the yeast replication origins ARS307. Deletion of the $\alpha 5$-helix, the potential cruciform binding domain of 14-3-3, decreased the cruciform binding activity of the protein as well as its association with the yeast replication origins ARS307 and ARSI. Furthermore, the mutant cells had a reduced ability to stably maintain plasmids bearing one or multiple origins.
\end{abstract}

Conclusion: 14-3-3, a cruciform DNA binding protein, associates with yeast origins of replication and functions as an initiator of DNA replication, presumably through binding to cruciform DNA forming at yeast replicators.

\section{Background}

Several studies have shown that cruciform DNA forms at or near eukaryotic origins of replication and is involved in the regulation of initiation of DNA replication $[1,2]$. In mammalian cells, cruciform extrusion is cell cycle regulated and reaches a maximum at the $\mathrm{G}_{1} / \mathrm{S}$ boundary [3]. The formation of cruciform DNA has also been shown in the Saccharomyces cerevisiae replication origin ARS307 [4], as revealed by specific anti-cruciform DNA monoclonal antibodies (mAbs) [5,6]. These mAbs have an enhancing effect on DNA replication, presumably through stabiliza- tion of cruciform structures forming at replication origins, which may function as recognition sites for the binding of regulatory proteins of DNA replication [1].

We previously purified from human (HeLa) cells a cruciform-specific binding protein, CBP [7] which was identified by sequence analysis as a member of the highly conserved 14-3-3 protein family [8]. The 14-3-3 proteins are mono- and hetero-dimeric molecules, conserved through plants, invertebrates, and higher eukaryotes (reviewed in [9]). There are at least seven distinct 14-3-3 
genes in vertebrates giving rise to nine isotypes $(\alpha, \beta, \gamma, \delta$, $\varepsilon, \zeta, \eta, \sigma$, and $\tau$, with $\alpha$ and $\delta$ being phosphorylated forms of $\beta$ and $\zeta$, respectively), while at least another twenty have been identified in yeast, plants, amphibians and invertebrates (reviewed in [10]). The 14-3-3 proteins are implicated in multiple cellular processes including signalling, cell cycle control, apoptosis, transcription and DNA replication (reviewed in [10-12]).

In mammalian cells, CBP activity occurs only when 14-33 is in a dimeric form [8]. Hydroxyl radical footprinting analysis localized the interaction of CBP with cruciform DNA to the four-way junction [13], conforming to the crystal structure of 14-3-3 [14,15], whereby the 14-3-3 dimers form a groove which provides the cruciform binding domain [13]. A similar interaction with the cruciform DNA has been found for the anti-cruciform monoclonal antibody 2D3 [16], suggesting the involvement of a common specific domain in both the 2D3 antibody and the 14-3-3 protein. Alignment of 2D3 antibody and 14-3-3e sequences revealed two domains of homology within the N-terminal residues of $14-3-3$ protein, with $40 \%$ similarity for positive residues in the $\alpha 5$-helix (data not shown). This domain is conserved in all 14-3-3 homologues and is located in the amphipathic groove, which is involved in nearly all the interactions of 14-3-3 with its protein partners [17], as well as in the binding to cruciform DNA [13].

In addition to its cruciform binding activity, CBP/14-3-3 was also shown to bind to mammalian replication origins in a cell cycle dependent manner, reaching a maximum at the G1/S boundary $[18,19]$. The role of $14-3-3$ in DNA replication, through direct association with replication origins, has not been determined yet. Proteomic analysis, however, indicated that 14-3-3 interacts with replication initiator proteins such as MCM3, Ku antigen [20,21] and MCM10 [22], implicating 14-3-3 in the regulation of initiation of DNA replication. The function of 14-3-3 proteins as a major regulator of the cell cycle has been reported in many studies. Thus, 14-3-3s regulate the cell cycle progression by sequestrating cell cycle proteins, like CDC25C [23] and p27 [24,25] in the cytoplasm. It has been also shown that 14-3-3 proteins have a temporal role in G1 arrest and S-phase checkpoint function [26].

The involvement of 14-3-3 in DNA replication has also been demonstrated in lower eukaryotes. In Saccharomyces cerevisiae, Bmh1 and Bmh2, the budding yeast 14-3-3 homologues $[27,28]$, also bind to cruciform DNA and associate in vivo with origins of replication [4]. In a recent study, 14-3-3 was also shown to be regulating the G1/S transition in the budding yeast ( $S$. cerevisiae), thus implicating it in the initiation of DNA replication [29]. The nature of replication origins (replicators) and the proteins that interact with them are key to understanding the mechanism regulating this process, which is conserved among lower and higher eukaryotes [30]. The replication origins of budding yeast cells have been well-characterized and used extensively to study the regulation of DNA replication. Furthermore, the genetic manipulations afforded by the yeast cells have made them very useful as host organisms to investigate the function of various proteins.

Taking advantage of these properties, here we analyzed the function of the human $14-3-3 \varepsilon$ protein, as the sole member of 14-3-3 in the $S$. cerevisiae cells, in terms of its cruciform binding activity and involvement in the initiation of DNA replication. The human $14-3-3 \varepsilon$ protein has more than $60 \%$ sequence similarity at the amino acid level with the budding yeast 14-3-3 protein homologues, Bmh1 and Bmh2. Deletion the $\alpha 5$-helix in 14-3-3e, as a potential cruciform binding domain, resulted in a markedly reduced yeast cell growth, as well as a decrease in cruciform binding activity and in the association of 14-3-3 with the yeast replication origins ARS307 and ARS1. Furthermore, the mutant cells showed a reduced ability to stably maintain plasmids bearing one or two origins. These results suggest that 14-3-3 is regulating DNA replication at the initiation level.

\section{Results \\ Expression of the wild-type and $\alpha$ 5-deleted human I4-3-3 $\varepsilon$ proteins in bmh I-bmh2 double knockout yeast cells}

The S. cerevisiae strain (GG1259), containing a genetic deletion of both the Bmh1 and Bmh2 proteins, is not viable. The viability of this strain is supported by the 14-3-3 Arabidopsis thaliana homologue protein, GF14, under the control of the inducible GAL1 promoter [31]. The wildtype and mutant ( $\alpha 5$-helix deleted) human $14-3-3 \varepsilon$ cDNAs were introduced in GG1259 cells, carried by the pEVP11-URA vector. This vector contains the constitutive $\mathrm{ADH}$ promoter, whose expression is increased in media containing glucose as a carbon source. The genomic uracil cassette in the GG1259 strain was removed to allow selection of pEVP11-URA+ clones. The new strains expressing the wild-type $14-3-3 \varepsilon$ (14-3-3ع) or $\alpha 5$-helix-deleted 14-3$3 \varepsilon$ (14-3-3- $\alpha 5)$ respectively, as the sole members of 14-33 proteins, were obtained by shuffling the plasmid carrying the GF14 gene.

As shown in Figure 1A, both the wild type and mutant strains, heretofore named $14-3-3 \varepsilon$ and $14-3-3-\alpha 5$ respectively, were viable, indicating that both the wild-type and the $\alpha 5$-helix-deleted 14-3-3ع complemented the S. cerevisiae bmh1-bmh2 double knockout. This strain (GG1259) can be complemented by several plant and human 14-3-3 homologues, some of which complement well and some very poorly [32]. The cells with GF14 alone (GG1259), named Gal GF14, on the other hand, were unable to grow 
in YPD media (Fig. 1A), ruling out the possibility of the participation of GF14 protein in the cell growth. As a positive control, Bmh1-Bmh2 wild type cells, named Bmh1/ 2 , were used to verify the yeast cell growth in normal conditions (Fig. 1A). To determine the effect of the mutation on cell cycle progression, both the wild type and mutant strains were grown in YPD and CSM-Trp (synthetic complete medium lacking tryptophan) media at $30^{\circ} \mathrm{C}$. In YPD, the mutant grew more slowly than the wild type strain. This slower growth was more pronounced in the selective (CSM-Trp) media (data not shown). The deletion of $\alpha 5$-helix in $14-3-3 \varepsilon$ conferred a slow-growth phenotype to the mutant cells compared to wild type, as seen when the cells were grown in YNB media, spotted onto YNB-Trp plates in 10-fold serial dilutions, and incubated at $30^{\circ} \mathrm{C}$ (Fig. 1B).

Having established that the viability of the yeast cells can be fully or partially supported by the wild type or the

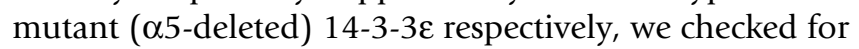
the presence of these two proteins by western blotting with anti 14-3-3E antibody (T16; Santa Cruz biotechnology) (Fig. 2A). Surprisingly, both the wild type and mutant $14-3-3 \varepsilon$ were detected by this antibody at the position of $30 \mathrm{kDa}$, indicating that the mutant migrated similarly to the wild type, in spite of the fact that it is lacking 20 amino acids of the $\alpha 5$-helix. A second band of $35 \mathrm{kDa}$ was typically detected by the anti-14-3-3e antibody, as also previously observed $[8,18]$. To rule out the possibility

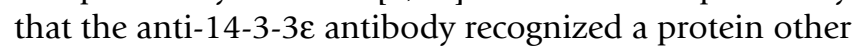
than the recombinant human $14-3-3 \varepsilon$ in the yeast background, yeast strains expressing the $\mathrm{Bmh} 1 / 2$ proteins or GF14 protein, were also used as controls (Fig. 2A). Only one of the two yeast 14-3-3 homologues was detected by the anti-human $14-3-3 \varepsilon$ antibody, with the same pattern as the human $14-3-3 \varepsilon$, while the GF14 protein was not detected at all. In contrast, when an antibody against Bmh1 protein $[4,33]$ was used in the same blot, both $\mathrm{Bmh} 1$ and Bmh2 proteins were detected (Fig. 2A, lower panel, lane Bmh1/2), while only one band was detected in yeast strains expressing the wild type and mutant $14-3-3 \varepsilon$ (Fig. 2A, lower panel, lanes $\varepsilon$ and $\varepsilon-\alpha 5$ ). This antibody also recognized the GF14 protein (Fig 2A, lower panel, lane GF14), in contrast with the anti human antibody. However, the 2 bands observed in GF14 are present in this protein even when it is blotted with anti-GF14 antibody, as detected in previous studies $[4,34]$. Thus, these bands are different from Bmh1 and Bmh2, since these 2 proteins are knocked-out in GF14 strain.

We examined next whether the observed growth defect was due to less expression or degradation of the mutant protein. It was recently reported that a cell growth defect in mutant yeast 14-3-3 was associated with a temperature sensitive (ts) phenotype [29]. A similar finding, however, was not observed for the mutant $14-3-3 \varepsilon$ in this study (data not shown), which prompted us to verify the amount of 14-3-3e present in growing (log-phase) cells. Whole cell extracts (WCE) from $10^{7}$ cells $\left(\mathrm{OD}_{600}\right.$ of 1.0$)$, were subjected to western blot analysis by immunoblot-

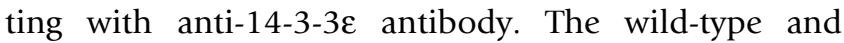
mutant proteins were similarly expressed (Fig. 2B,C), suggesting that the mutation did not affect the expression level of this protein, and that any other observed effect in the mutant cells would be specifically functional. Furthermore, since 14-3-3 proteins associate with multiple protein partners as well as with cruciform DNA, we verified whether these associations affected the affinity of the anti14-3-3 $\varepsilon$ antibody for the protein. WCE from formaldehyde-fixed cells were also subjected to western blotting (Fig. 2B), and quantification of the bands showed (Fig. 2C) that formaldehyde treatment had no effect on the amount of 14-3-3 present in the extracts.

\section{Effect of $\alpha 5$-helix deletion in 14-3-3 $\varepsilon$ on cruciform-binding activity}

Since both the wild-type and the $\alpha 5$-helix-deleted human $14-3-3 \varepsilon$ support the viability of the yeast cells, we ana-

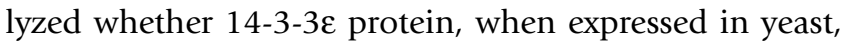
conserved its cruciform binding activity and whether deletion of its potential cruciform domain affected this activity. Comparative band-shift analyses (Fig. 3A), using whole cell extracts from cells expressing either wild-type (lane 2) or mutant (lane 3) 14-3-3ع, indicated that the mutant $14-3-3 \varepsilon$ protein had a decreased mobility shift compared to the wild-type. To verify the presence of 14-3$3 \varepsilon$ in the band-shifted complexes, the proteins were eluted (see Methods) and analyzed by western blotting, using the


type and mutant 14-3-3 proteins were detected (Fig. 3B), with both the major $30 \mathrm{kDa}$ and the less intense $35 \mathrm{kDa}$ bands being present, as always detected by the anti-14-3$3 \varepsilon$ antibody $[8,19]$.

Because the mutation in $14-3-3 \varepsilon$ is the sole difference between the two cell extracts, and the fact that 14-3-3 binds physically [8] and specifically [13] to cruciform DNA, the data also suggest that $\alpha 5$-helix is only partially responsible for the cruciform binding activity, since its deletion did not completely abolish it. The reduction in the mobility shift might not be attributable to the shorter length of the deleted protein, as also shown previously in similar studies $[35,36]$. However, to better characterize

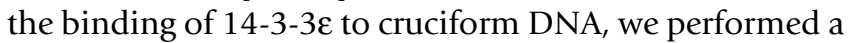
protein concentration curve (Fig 3C). The results show that for both the wild type and the mutant proteins, the shifts are protein concentration dependent and proportional to the amounts of the proteins added. Nevertheless, for any amount of total proteins used, the band shift produced by the mutant strain extract is lower than the wild 


\section{YPD at $30^{\circ} \mathrm{C}$}


\section{YNB-Trp at $30^{\circ} \mathrm{C}$}



Figure I

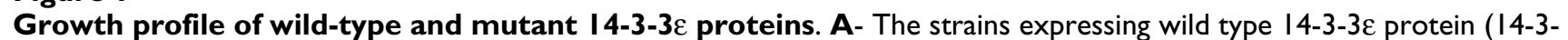
$3 \varepsilon$ ), mutant $14-3-3 \varepsilon$ protein ( $\mid 4-3-3-\alpha 5)$, GFI4 protein (GalGFI4) and BY427 expressing BmhI and Bmh2 proteins strain $(\mathrm{Bmhl} / 2)$ (used as a positive control), were streaked on a YPD plate and incubated at $30^{\circ} \mathrm{C}$ for 3 days. B- Cells were grown in YNB media, spotted onto YNB-Trp plates in 10 -fold serial dilutions, and incubated at $30^{\circ} \mathrm{C}$. 
A

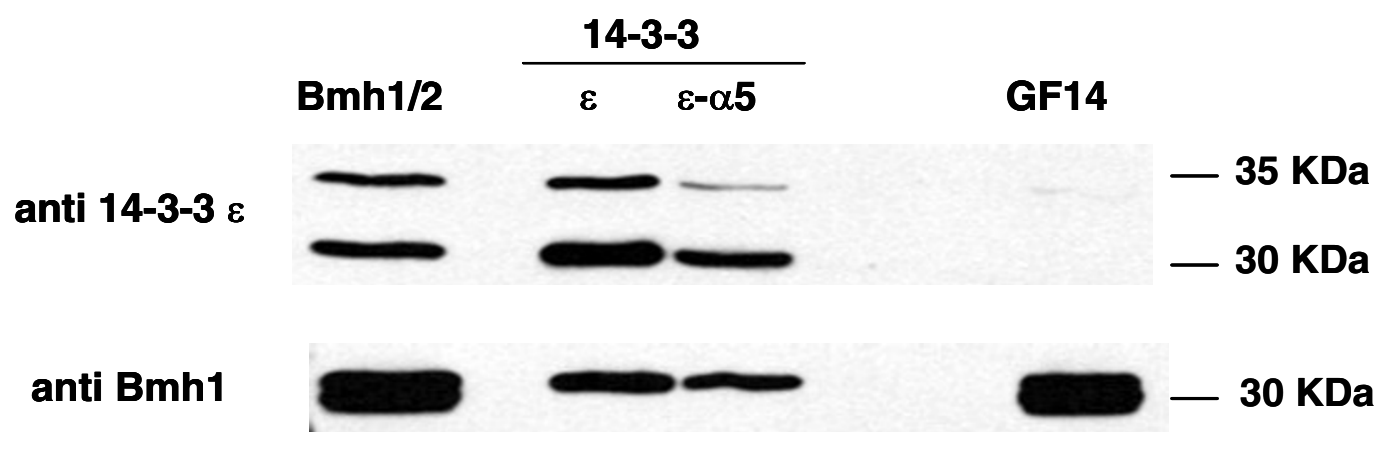

B

Formaldehyde

14-3-3e Ab

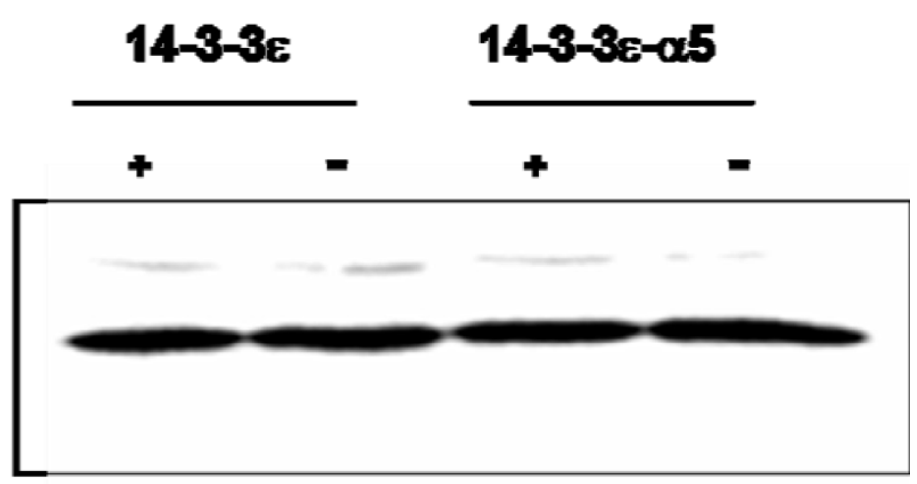

C

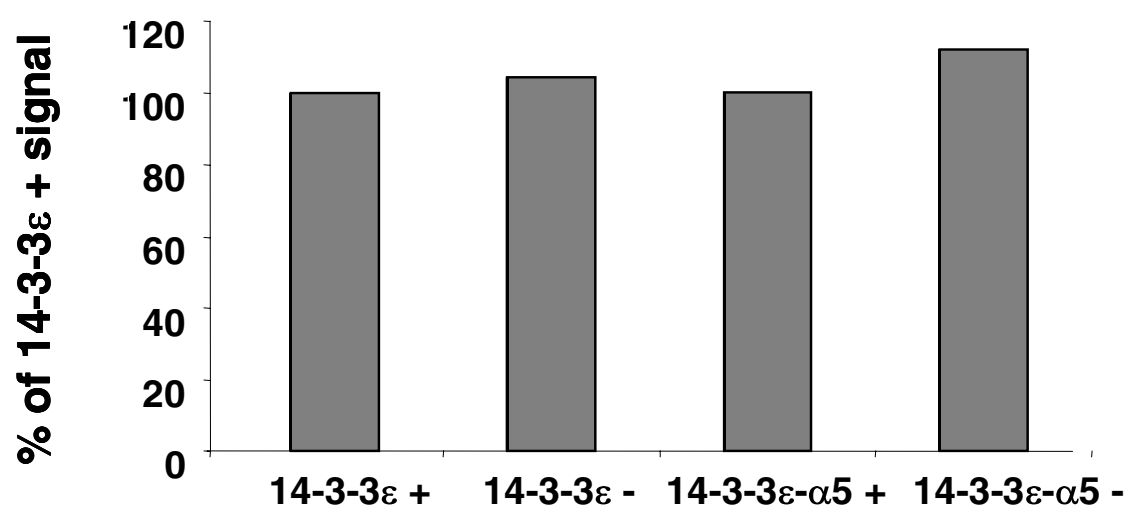

Figure 2

Western blot analysis of wild-type and mutant 14-3-3 $\varepsilon$ proteins. A- Whole cell extracts (WCE) of the wild-type(I4-3$3 \varepsilon$ ), the $\alpha 5$-helix-deleted (I4-3-3- $\alpha 5)$ I4-3-3 $\varepsilon$, as well as Bmh I/Bmh2 and GFI4 proteins-expressing cells, were prepared and $20 \mu \mathrm{g}$ of total protein of each were subjected to electrophoresis on a I2\% SDS polyacrylamide gel. All proteins were revealed by probing with anti- $\mid 4-3-3 \varepsilon$ antibody and anti-BmhI antibody. B- Expression of the wild type and the mutant I4-3-3 $\varepsilon$ in the presence and absence of formaldehyde, detected by anti-|4-3-3E antibody. C- Quantification of the immunoblots after normalization for the formaldehyde crosslinked $14-3-3 \varepsilon$. 


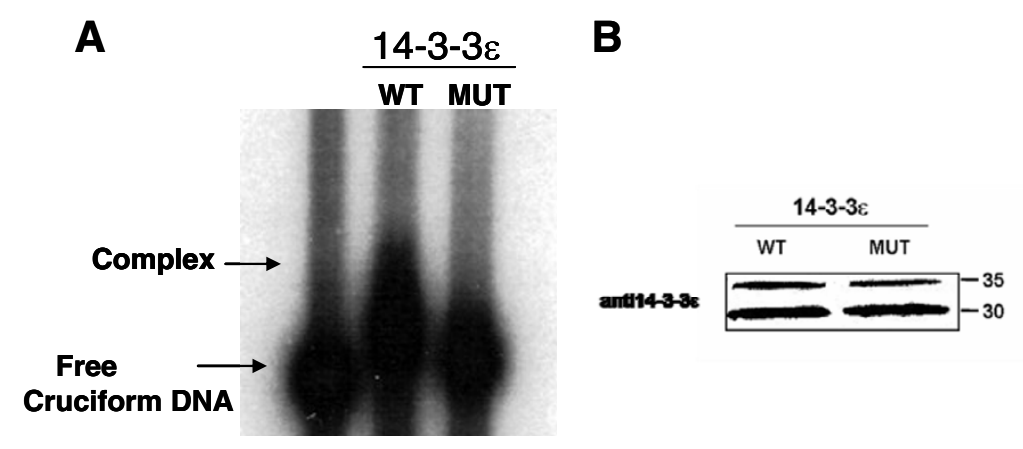

\section{C}

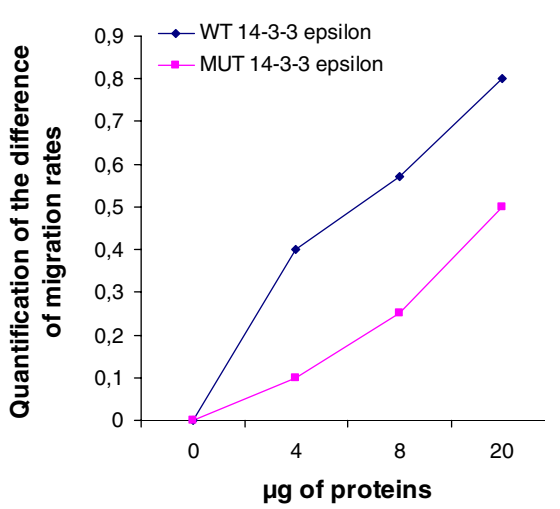

D

$\mathbf{E}$

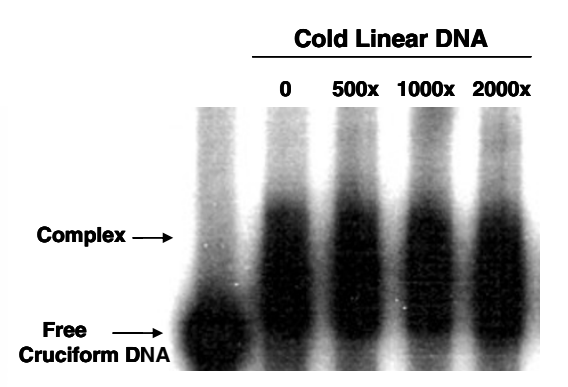

Figure 3

Cruciform-binding activity of 14-3-3e. Band shift assays were carried out as described in Methods. A- 3 ng of $32 \mathrm{P}-\mathrm{labelled}$ cruciform DNA was incubated in the presence of $20 \mu \mathrm{g}$ of wild-type (lane2) or mutant (lane 3) total whole cell extracts. Free cruciform DNA denotes the position of the probe alone. B- Western blot of proteins eluted from band-shifts initially performed with $300 \mathrm{ng}$ of labelled cruciform DNA, and probed with anti- I4-3-3E antibody (see Methods). C- Representative protein concentration curve using increasing amounts of total WCE containing wild type or mutant $14-3-3 \varepsilon$ proteins incubated with $3 \mathrm{ng}$ of cruciform DNA. Differences of migration rates of the shifted complexes with free cruciform DNA are represented with arbitrary units. D-E- Competition binding assays were carried out as described in Methods. Cold cruciform DNA (D) and cold linear DNA (E) competitors were added in the indicated amounts in a reaction with wild type I4-3-3E. Free cruciform DNA denotes the position of the probe alone.

type, suggesting that the deletion of the $\alpha 5$-helix in 14-3$3 \varepsilon$ is responsible for this reduction.

It has been previously shown that CBP/14-3-3 recognizes and binds to cruciform DNA specifically by structure rather than sequence $[4,7]$. To verify the specificity of the binding to cruciform DNA by the yeast-expressed 14-3-3e, competitive band-shift assays were performed, using increasing amounts of cold cruciform or cold linear DNA to compete with the labelled cruciform in the binding reaction, as previously described [7]. As shown in Figures $3 \mathrm{D}$ and $3 \mathrm{E}$, the mobility shift of the cruciform-14-3-3E complex decreased progressively with higher molar excess of cold cruciform competitor, and was nearly completely abolished at a molar excess of $500 \times($ Fig. 3D), while up to
$2000 \times$ of cold linear DNA did not compete with the cruciform complex formation (Fig. 3E).

Furthermore, to determine whether the inhibition of the cruciform binding activity in the mutant protein might be due to a disruption of the site involved in the interactions of 14-3-3 with its protein partners, which is located in the groove [17], we analyzed the effect of addition of the 143-3 peptide inhibitor, R18 (Biomol International, LP) on the $14-3-3 \varepsilon$ expressing yeast extract. In mammals, R18 binds with the same affinity to all 14-3-3 isoforms and disrupts their substrate binding [37]. A concentration of $25 \mu \mathrm{M}$ of R18 has been shown to inhibit the interaction of 14-3-3 proteins with their proteins partners in HeLa cells extract [38]. However, since there is no previous character- 
ization of the effect of R18 in yeast extract, we analysed the ability of this inhibitor to disrupt the interaction of 14-3$3 \varepsilon$ with Ras 2 protein, a known $14-3-3 \varepsilon$ binding partner [39]. The results show clearly that the yeast Ras 2 protein immunoprecipitates with $14-3-3 \varepsilon$ in the absence of R18, as indicated in the western blot by the band at $40 \mathrm{kDa}$, while this band is completely absent after addition of 100 $\mu \mathrm{M}$ of R18 (Fig. 4A). WCE from a Bmh $1 / 2$ expressing cells was used as a positive control. These data suggest that R18 functions in yeast as an inhibitor of 14-3-3 interactions, in the same way as in mammalian cells.

Based on these results, we next analyzed the binding activ-

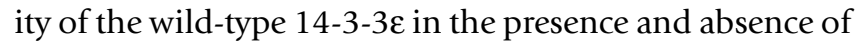
$\mathrm{R} 18$. Even after using an excess amount (up to $100 \mu \mathrm{M}$ ) of R18 in the cruciform binding assay, band shift analyses showed that the cruciform binding activity of $14-3-3 \varepsilon$ is not affected by R18 treatment (Fig. 4B). Addition of very high concentration of R18 $(100 \mu \mathrm{M})$ resulted in higher intensity of the same complex seen in the absence of R18 (Fig. 4B, last lane). These data suggest that $14-3-3 \varepsilon$ binds to cruciform DNA even when its protein binding site is inhibited by R18 peptide, ruling out the possibility that another 14-3-3 partner is involved in this activity. Thus, overall the data suggest that the reduced cruciform binding activity of the mutant $14-3-3 \varepsilon$ is specifically related to the deletion of the $\alpha 5$-helix.

\section{Association of wild-type and $\alpha 5$-helix deleted $14-3-3 \varepsilon$ with yeast replication origins}

The budding yeast ( $S$. cerevisiae) replication origin ARS307 has been well characterized [40,41]. Among other DNA sequence features, it contains an inverted repeat (IR), which extrudes into a cruciform structure, as shown by immunoprecipitation (IP), using the specific anti-cruciform DNA monoclonal antibody, 2D3 [4]. Since both wild type and mutant $14-3-3 \varepsilon$ proteins support the viability of the budding yeast strains, we examined their association with the replication origin ARS307 by the chromatin immunoprecipitation (ChIP) assay, using formaldehyde cross-linking and immunoprecipitation with anti-14-3-3e antibody or normal rabbit serum (NRS), as previously described $[4,19]$. Extracts from wild type and mutant yeast strains containing the same amount of total protein (1 $\mathrm{mg})$, were subjected to immunoprecipitation using anti14-3-3e antibody. The western blot (W.B) shows that in both IPs, the antibody precipitated approximately the same amount of $14-3-3 \varepsilon$ (Fig. 5A), while NRS failed to immunoprecipitate it. A WCE containing only $14-3-3 \varepsilon$ was used as a positive control (Fig. 5A). These results validated the ChIP assays and have been used as control for the quantification of the immunoprecipitated DNA. The obtained ChIP materials were subjected to conventional PCR using primers specific for ARS307. The results show that for the anti-14-3-3ع antibody ChIP, an expected 370- bp ARS307 fragment was amplified (Fig. 5B, lane 1, upper and bottom panels, respectively). In contrast, PCR amplification of the chromatin that was immunoprecipitated by the pre-immune serum, did not produce this fragment (Fig. 5B, lane 2, upper and bottom panels, respectively), confirming the specificity of the amplification, whereas use of WCE from the 14-3-3e wild type (lane 3, upper panel) and the mutant (lane 3, bottom panel) strains, or of $S$. cerevisiae genomic DNA (lane 4, upper and bottom panels, respectively) as template DNA did. The plasmid pRS306, containing ARS307 cDNA (lane5, upper and bottom panels, respectively), was used as an additional positive control of the PCR reactions. These data showed that the human $14-3-3 \varepsilon$ protein, like its yeast homologues, can associate with the yeast replication origin, ARS307, and indicated the universality of the origin binding activity of 14-3-3 proteins.

To better analyze the effect of the $\alpha 5$-helix deletion in 14$3-3 \varepsilon$ on its ability to bind to replication origins, the amount of origin-containing immunoprecipitated chromatin was quantified by Real-time PCR using two different origins (ARS307 and ARS1) and their respective negative regions (Neg307 and R2.5). Cross-linked whole cell lysates, containing either wild-type or $\alpha 5$-helixdeleted 14-3-3ع protein, were normalized to $20 \mu \mathrm{g} / \mu \mathrm{l}$ and

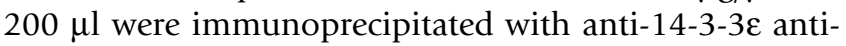
body or NRS. The immunoprecipitated chromatin obtained in each ChIP assay was then quantified by Realtime PCR, using the regions indicated above as template DNA and the specific primers for amplifying each region (see table 1). The quantity of PCR product from each template is calculated at the threshold of amplification determined by the light-cycler software (Roche) by comparison to the values of the genomic standard curve. As shown in Figure 5C, these values (histogram bars) represent the amount of chromatin immunoprecipitated in each sample, reflecting the number of DNA molecules initially used in the Real-time PCR reaction. The results indicated that the association of 14-3-3e with ARS307 and ARS1 decreased by approximately $40 \%$ in the mutant cells, an effect that may be directly attributed to the deletion of the $\alpha 5$-helix in $14-3-3 \varepsilon$, as it is the sole physiological difference between the wild-type and mutant cells. In contrast, in the respective negative regions of ARS307 and ARS1 (Neg307 and R2.5 respectively), the amount of immunoprecipitated DNA was not significantly different between the wild-type and the mutant cells. These amounts were also comparable to the number of molecules brought down non-specifically by NRS in both cell types. Taken together, these data suggest that $14-3-3 \varepsilon$ binds specifically to origins of replication in yeast, and that the decreased association with origins in the mutant cells is likely a direct effect of the deletion of the $\alpha 5$-helix in $14-3-3 \varepsilon$. 


\section{A}

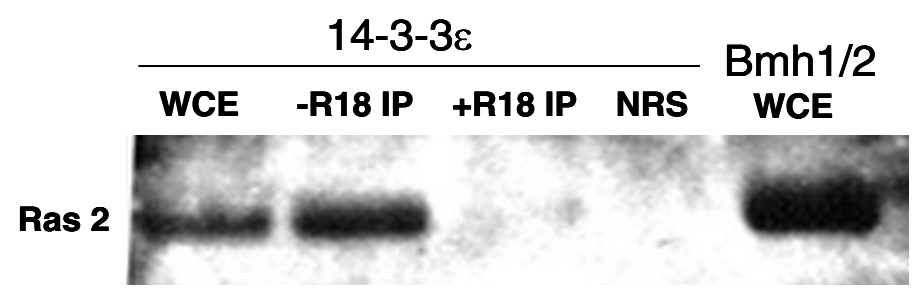

B

\section{R18}

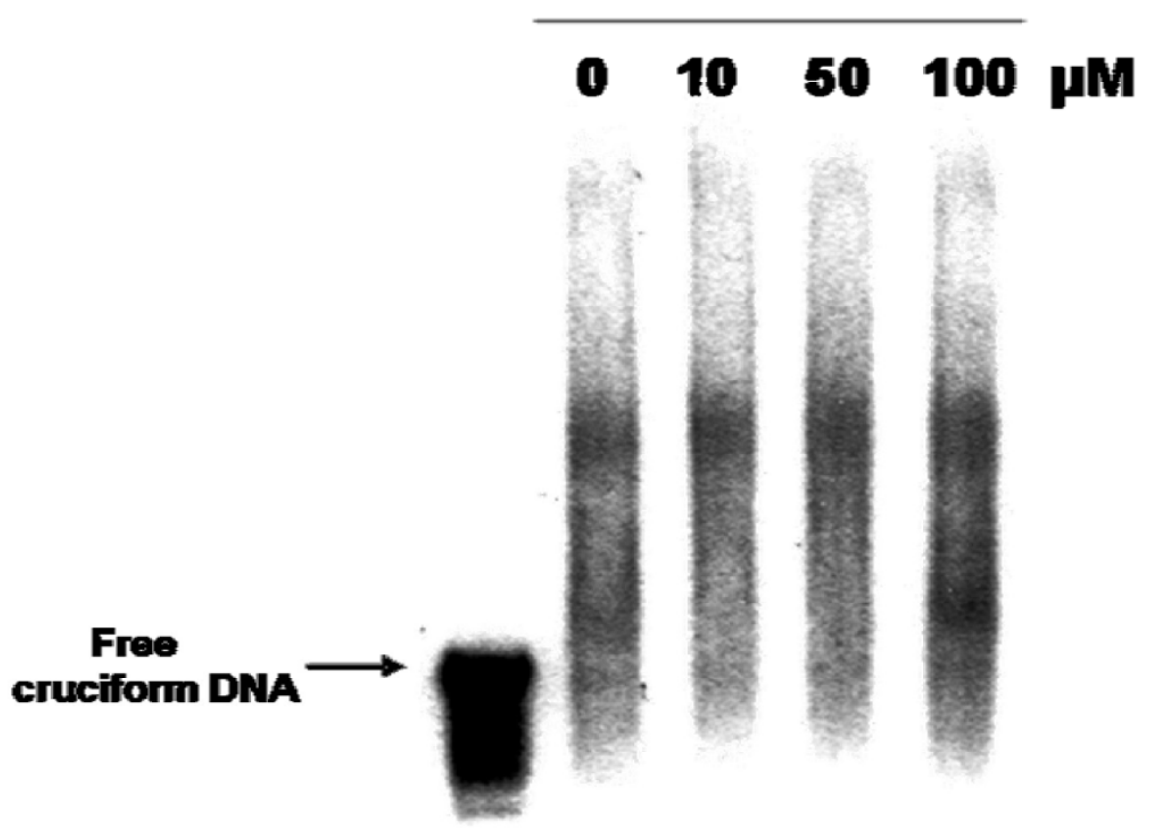

\section{Figure 4}

Effect of RI 8 on cruciform-binding activity. Lysate was prepared from yeast cells expressing wild-type $\mid 4-3-3 \varepsilon$ as described in Methods under the WCE preparation section. A- Total protein extract $(\mathrm{I} \mathrm{mg})$ was incubated at $30^{\circ} \mathrm{C}$ for $30 \mathrm{~min}$ in the absence or presence of $100 \mu \mathrm{M}$ of R 18 peptide, followed by immunoprecipitation with anti $14-3-3 \varepsilon$ antibody and blotted with anti-Ras2 antibody. Immunoprecipitation with normal rabbit serum (NRS) and a Bmh I/2-expressing strain were used as controls. B- $14-3-3 \varepsilon$ protein extracts were incubated in the same conditions as in section A with increasing amounts $(10,50$ and $100 \mu \mathrm{M}$ ) of R 18 , and then subjected to a cruciform binding assay, as described previously (see Methods). Free cruciform DNA denotes the position of the probe alone. 
A

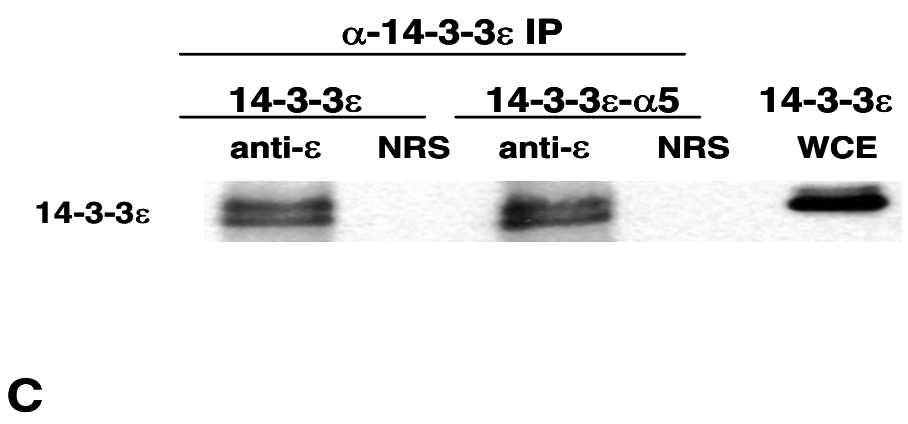

B

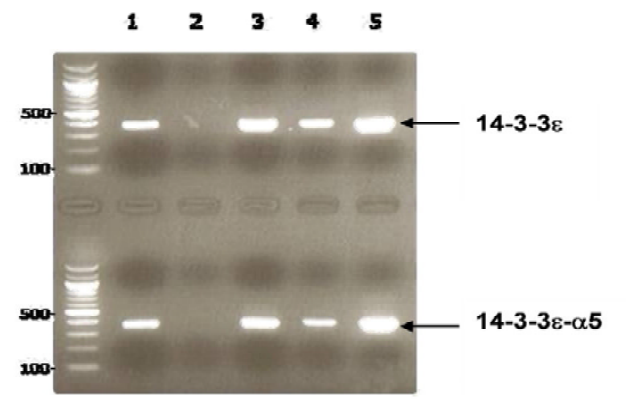

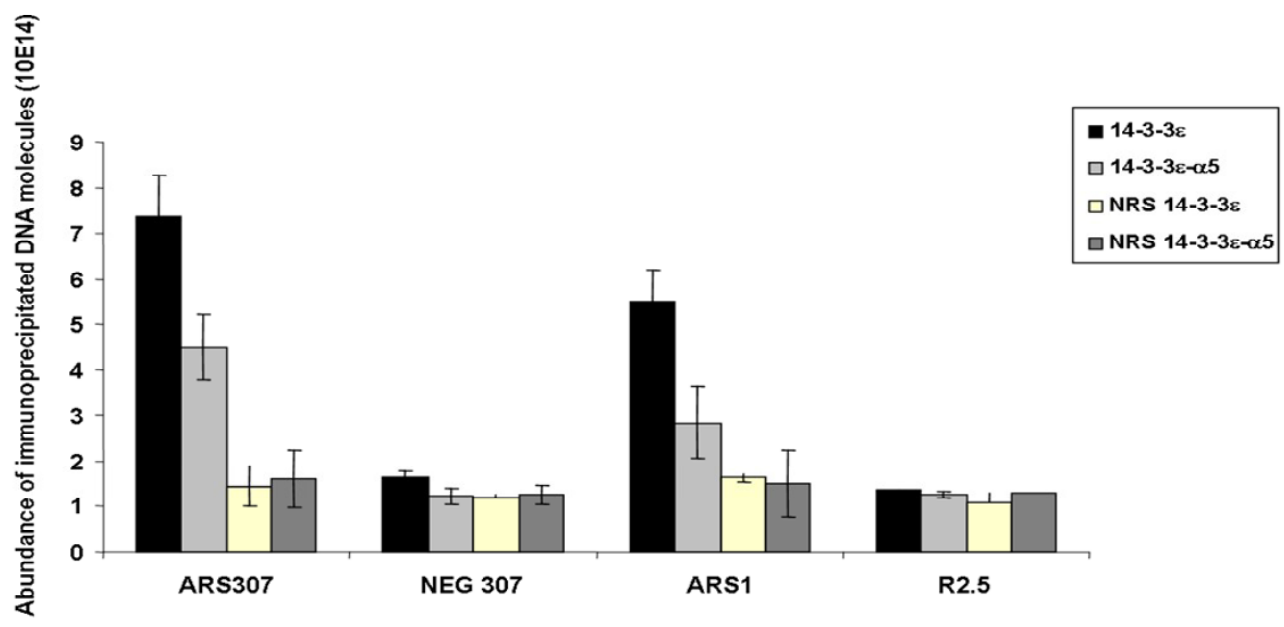

\section{Figure 5}

Chromatin immunoprecipitation assays. A-Formaldehyde cross-linked WCEs were immunoprecipitated with anti-14-3$3 \varepsilon$ antibody. Approximately the same amount of wild type and mutant $14-3-3 \varepsilon$ were revealed by the anti-14-3-3 $\varepsilon$ antibody. NRS and I4-3-3E WCE were used as controls for the IP. B- The immunoprecipitated chromatins were subjected to conventional PCR and resolved in a I.5\% agarose gel. Upper panel of the gel shows the PCR products of the ChIP performed with

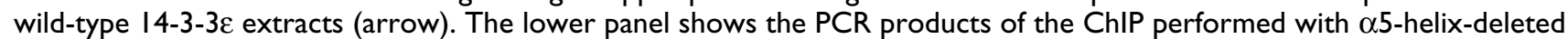

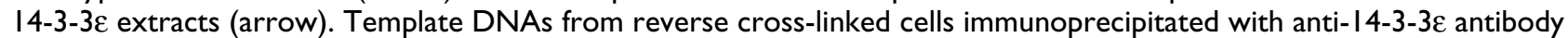
(lane I) or pre-immune sera (lane 2), wild-type and mutant yeast WCE (lane 3 in upper and lower panel respectively); I0 ng of genomic DNA (lane 4) and $10 \mathrm{ng}$ of plasmid pRS306 containing ARS307 (line 5), were used as controls. C- The amounts of wild-type or $\alpha 5$-deleted I4-3-3 $\varepsilon$ proteins associated with ARS307, ARSI and their negative regions, Neg307 and R2.5 respectively, were measured by Real-time PCR. Cross-linked WCE were immunoprecipitated using anti-14-3-3E antibody or NRS, and each corresponding ChIP material was used as template DNA. Error bars represent the average of three separate experiments and one standard deviation.

\section{Plasmid stability assay}

DNA cruciforms have been implicated in the initiation of DNA replication by acting as regulatory signals at origin sites at the onset of S-phase (reviewed in [2]). Furthermore, 14-3-3 proteins have higher cruciform binding (CBP) [2] and origin association [19] activities at the G1/ $S$ boundary. In view of these observations, and in order to test the hypothesis that $14-3-3$ is a regulatory protein at the initiation level of DNA replication, we analyzed whether deletion of the $\alpha 5$-helix in $14-3-3 \varepsilon$ affected the maintenance and initiation of DNA replication of minichromosomes (ARS-containing plasmids). In S. cerevisiae, characterization of ARS function was largely done by using a plasmid stability assay $[40,41]$.

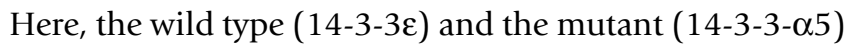
yeast strains were used to measure plasmid loss rates, using a pair of test plasmids, containing either a single 
Table I: Sequences of primers used for the constructs and the LightCycler

\begin{tabular}{|c|c|}
\hline Primers & Sequences \\
\hline \multicolumn{2}{|c|}{$\alpha 5$-helix deletion } \\
\hline Fragment I-F & 5' CGGAATTCATGGATGATCCGAGAGGATCTG 3' \\
\hline Fragment 2-F & 5' GCTCTAGATCACTGATTTTCGTCTTCCAC 3' \\
\hline Fragment I-R & 5' CGCCTTGGACTCGCCAGTGTTAGCTGC 3' \\
\hline Fragment 2-R & 5' GCCCAAGGCCACAGGAAACGACAGGAAGG 3' \\
\hline \multicolumn{2}{|c|}{ PCR of ARS307 } \\
\hline ARS307-F & 5' ATATTGCAATTACTTCTTCTCATGCAC 3' \\
\hline ARS307-R & 5' ATATTGCAATTACTTCTTCTCATGCAC 3' \\
\hline PARS307-F & 5' GGTAGGGATAATAATCTGTAATGAGGA 3' \\
\hline PARS307-R & 5' TATGTCGACGAGTGAGTTGGA 3' \\
\hline \multicolumn{2}{|c|}{ Real-Time PCR } \\
\hline RT-ARS307-F & 5' GCAGTAGCACATGGACACATTCAC 3' \\
\hline RT-ARS307-R & 5' AGGGTTTCTGGAGAGGTAGGGATA 3' \\
\hline NegARS307-F & 5' ATTTTGTGGTGGATTGGAG 3' \\
\hline NegARS307-R & 5' GCTTGTTTGTGCAACTAAACG 3' \\
\hline ARSI-F & 5' GAAAATAGGTTATTACTGAGTAG 3' \\
\hline ARSI-R & 5' CCTGCGATGTATATTTTCCTG 3' \\
\hline $\mathrm{R} 2.5-\mathrm{F}$ & 5' CATCAATTGTGCACTCGGAC 3' \\
\hline $\mathrm{R} 2.5-\mathrm{R}$ & 5' GAACACGGCAATTGTAGGTGG 3' \\
\hline
\end{tabular}

ARS, pARS-1 (containing ARSH4) or two, pARS-2 (containing ARSH4 and ARS307) (see Methods). In all the previously characterized mutants of proteins involved in the initiation of DNA replication, such as ORC, Cdc6, MCM, and Cdc45, plasmids containing a single replication origin had higher plasmid loss rates than plasmids containing multiple replication origins, while wild-type cells lost both test plasmids at equally low rates $[42,43]$.

As shown in Figure 6, deletion of the $\alpha 5$-helix in 14-3-3e compromised the mutant cells, containing 14-3-3e- $\alpha 5$ protein, in their maintenance of the minichromosome pARS-1, showing a plasmid loss rate of approximately $5 \%$ per generation. In contrast, when pARS- 2 was expressed in these cells, the plasmid was more stable by approximately 2.5-fold. When the same assay was performed using wildtype cells, both test plasmids were lost at a much lower rate of approximately $1-1.4 \%$ per generation. These results indicated that the deletion of the $\alpha 5$-helix in 14-3$3 \varepsilon$ was responsible for the higher plasmid loss rate, suggesting that this protein regulates DNA replication at the initiation level.

\section{Discussion}

In the present study, we analyzed the effect of deleting the $\alpha 5$-helix domain of $14-3-3 \varepsilon$ on its cruciform binding and replication origin binding activities as well as on the initiation of DNA replication. The results show that the human $14-3-3 \varepsilon$ protein can replace its counterparts, Bmh1 and Bmh2, in $S$. cerevisiae, as yeast cells expressing only human $14-3-3 \varepsilon$ were viable. Previous studies have shown that the human cruciform binding protein $\mathrm{CBP} /$ 14-3-3 associates in vitro with cruciform-containing DNA
[13] as well as in vivo with mammalian origins of DNA replication [19]. The Bmh1 and Bmh2 proteins have been shown to have the same activities as their mammalian homologues, namely the 14-3-3 proteins [4]. CBP association with cruciform DNA occurs only in the dimeric form of the protein [8], mainly in a heterodimeric conformation with a preferential pattern of heterodimerization [44]. Furthermore, using different genetic backgrounds of yeast, it was previously shown that the Bmh1-Bmh2 heterodimer was more efficient in binding to cruciform DNA than the homodimer of either protein [4]. Here, we have shown that the human $14-3-3 \varepsilon$ expressed in yeast conserves its cruciform binding activity, indicating that it can dimerize with itself and functions as a homodimer. Previous studies on dimer profile analysis reported that endogenous $14-3-3 \varepsilon$ isoform was never found as a homodimer $[45,46]$. This discrepancy may be explained by the preferential pattern of dimers adopted in mammalian cells, which is not afforded in the yeast strains used in this study. Furthermore, it was previously shown that the 143-3 plant homologue GF14 was also able to homodimerize and binds to cruciform DNA [4].

Although the mode of association of CBP/14-3-3 with cruciform DNA has been previously shown [13], the regions of 14-3-3 responsible for this activity have not been determined yet. Thus, hydroxyl radical footprinting analyses showed that CBP binds to cruciform DNA at the four-way junction [13], as does the anti-cruciform antibody, 2D3 [16]. Taken together, these results suggested the involvement of a common domain(s) between $\mathrm{CBP} /$ 14-3-3 protein and 2D3 antibody responsible for CBP activity. Alignment of $14-3-3 \varepsilon$ and $2 \mathrm{D} 3$ amino acid 


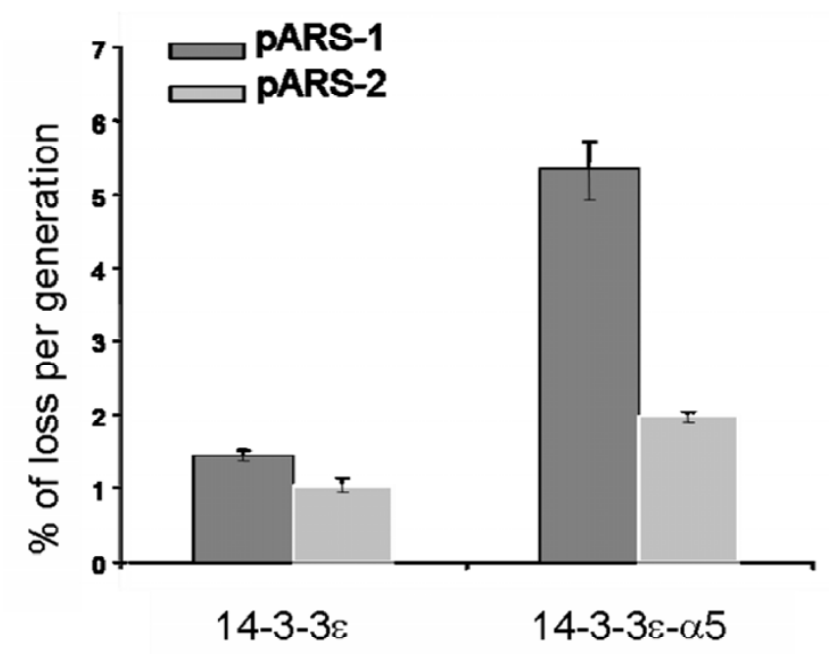

Figure 6

Plasmid stability assay. Plasmid loss rates were measured for the wild-type and $\alpha 5$-deleted $14-3-3 \varepsilon$ yeast cells containing either PARS-I or PARS-2. Plasmid loss rates are expressed as the average of percent loss per generation. Error bars represent the average of three separate experiments and one standard deviation.

sequences revealed a $23 \%$ identical (40\% identical when positive charges residues are taken in account) region, corresponding to the $\alpha 5$-domain in $14-3-3 \varepsilon$ protein (amino acids 119-169). Crystallography of 14-3-3 protein showed that the molecule is a cup-shaped dimer $[14,15]$. Each monomer contains nine $\alpha$-helices (denoted $\alpha 1-\alpha 9$ ), with the dimer interface formed from helices $\alpha 1, \alpha 3$ and $\alpha 4$, while helices $\alpha 5-\alpha 9$ form an amphipathic groove that is considered as the binding domain of the protein [17]. This information argued strongly for a possible involvement of the 14-3-3 $\alpha 5$-domain in cruciform binding activity and regulation of DNA replication, and prompted the analysis of the effects of its deletion on these processes.

As shown above, although both the wild-type and $\alpha 5$ deleted $14-3-3 \varepsilon$ were able to bind cruciform DNA, the DNA-protein complex formed with the mutant protein exhibited a lower band-shift than the one formed with the wild-type, indicating an inhibitory effect of the $\alpha 5$-deletion on the cruciform binding (CBP) activity. The $\alpha 5$ domain, however, seemingly participates partially in this activity, since its deletion did not completely abolish CBP activity. Considering that 14-3-3 binds to cruciform DNA in a structure-specific manner [7], the domains adjacent to the $\alpha 5$-helix might contribute to its full activity, as it is the case for the interactions of 14-3-3 with other proteins [17]. Alternatively, the difference in the cruciform mobility-shift might be due to changes in the conformation of the cruciform DNA molecule upon binding to the mutant protein. It was shown previously that CBP/14-3-3 binding can cause structural alterations in the DNA, thereby presenting the appropriate signals for DNA replication [13]. The band-shift patterns obtained in this study may have arisen because the mutated 14-3-3e might not be able to induce the proper structural alterations in the cruciform forming within the origin, which may either result in a less stable cruciform or alter the ability of other proteins to bind to the origin. Cruciform stabilization at replication origins has been shown to be induced by the anti-cruciform DNA antibody, 2D3 [1].

14-3-3 proteins associate in vivo with replication origins in mammalian [18] and yeast [4] cells. In this study, we showed for the first time that a human $14-3-3 \varepsilon$ was able to bind specifically to active yeast origins of replication, ARS307 and ARS1, while deletion of the $\alpha 5$-helix in 14-3$3 \varepsilon$ decreased its association with these origins. The sequence requirements for replication origin activity vary considerably between different eukaryotic organisms. In $S$. cerevisiae, these sequences consist of an essential A element, containing the ARS consensus sequence (ACS) [47] and two or three important B elements that are collectively required for origin function [40]. Initiation of replication requires the presence of ACS, which together with the $\mathrm{B} 1$ element forms the binding site of the origin recognition complex (ORC) [48]. ORC remains stably bound to the chromatin throughout the cell cycle [49], and recruits other proteins to the origin in a cell cycle regulated manner [50]. In higher eukaryotes, the molecular basis of origin identity and function is less well understood. Indeed, the cis-acting sequences required to direct the initiation of DNA replication are more complex and may extend over thousands of base pairs of DNA in mammalian origins [51]. Like in S. cerevisiae, these sequences direct the formation of a number of protein complexes leading to the assembly of the pre-replicative complex (pre-RC) at origins during G1 [30]. These proteins include, among others that are conserved, ORC homologues that have been identified in all eukaryotes [52]. The sequence preference for ORC binding is not absolute in metazoa, suggesting that there may be other factors that increase the affinity of ORC binding to origins [53]. These factors include proteins such as the recently identified initiator protein OBA/Ku86 [54]. Although there is no apparent sequence homology between mammalian and yeast origins, previous studies as well as the data here suggest that 14-3-3 binds to a common structural feature in these different origins, namely cruciform DNA. Furthermore, considering that $14-3-3$ is a cruciform binding protein, and the fact that several isoforms of this protein have been immunoprecipitated with cruciform structures present in mammalian and yeast replicators [4], it may be concluded that 14-3-3 proteins bind to active yeast and mammalian origins at cruciform structures. 
In this study, we have also identified 14-3-3 as a novel initiator protein for yeast DNA replication. 14-3-3 proteins are known to be important regulators of vital cellular functions such as transcription, cell cycle control and signal transduction. It is thus reasonable to assume that the replication initiation phenotypes of the $\alpha 5$-helix-deleted 14-3-3e might be the indirect result of an aberrant transcription or regulation of other initiator proteins. The role of 14-3-3 in the regulation of transcription in S. cerevisiae has been recently investigated, using a bmh2-ts mutant [33]. That study revealed that the yeast 14-3-3 homologues stimulate the transcription of many genes involved in ergosterol metabolism and in stress response, but found no alteration in the transcription of initiator proteins like ORC, Cdc6 or MCM proteins. 14-3-3 has also been shown to regulate the transcription of inducible genes by regulating the function of the histone $\mathrm{H} 3$ protein [55]. However, the association of 14-3-3 with DNA bound to histone $\mathrm{H} 3$ cannot explain the decrease of the association of the mutant 14-3-3 with the origin in this study, because the region of the chromosome that is affected is limited to origin containing DNA. Furthermore, the association between 14-3-3 and histone proteins is not systematic. In a recent study, a GINS complex responsible for fork progression during DNA synthesis was purified [56] and found to contain the four histone proteins but no 143-3. In general, the notion that 14-3-3 may play an indirect role in replication by controlling transcription or even protein-protein interactions would be incompatible with the fact that 14-3-3 physically interacts with replication origins, as shown previously [19] and here by the ChIP assay. Furthermore, the data in this study indicate that 14$3-3 \varepsilon$ plays a direct role in the initiation of DNA replication, as it is required for the maintenance of a minichromosome, as assayed by plasmid loss rate of two ARScontaining plasmids. This assay can reveal whether a mutant is likely defective in the initiation of DNA replication [42].

Lottersberger and co-workers [29] showed in a recent study that some bmh1-ts mutants had growth defects, which may be related to a low expression of G1 cyclincdk1. They attributed the cell cycle arrest to a decrease in the level of CLN2 protein (one of Cdk1 subunits) in the bmh1 mutants, where there was a complete G1/S arrest after shifting to $37^{\circ} \mathrm{C}$. This statement was not necessarily true for the other mutants used in the same study, where the G1/S transition was only delayed. In our study, we observed a slow growth in the 14-3-3e- $\alpha 5$ protein expressing cells. This growth defect is most likely not attributable to a lower expression of the G1 cyclin-cdk1, since our mutant cells are not temperature sensitive and do not represent any noticeable difference in the cell cycle distribution in log phase (data not shown). Rather, it might be explained, at least in part, by the results from the plasmid stability assays, given the extent of the loss viability observed in the mutant cells. This assay indicates that the mutation in $14-3-3 \varepsilon$ is affecting the initiation of DNA replication most likely by disrupting its direct association with origins of replications sites. Nevertheless, given the effect of 14-3-3 proteins on different regulatory processes, such as transcription and cell cycle progression, it is possible that other mechanisms also contribute to this growth defect.

\section{Conclusion}

Overall, the data presented here attest to the universality of binding of 14-3-3 proteins to replication origins and their involvement in the regulation of DNA replication. Our data, coupled with the apparent function of 14-3-3 proteins in the G1/S transition [19], and the role of cruciform DNA in the initiation of replication [1], suggest that 14-3-3 may function in the initiation of DNA replication by regulating the formation or maintenance of the pre-RC through interactions with cruciform DNA. To elucidate the exact mechanism of this process, the association of 143-3 with other initiator proteins, as well as the cell cycle profile and regulation of these proteins in budding yeast are currently being investigated.

\section{Methods \\ Strains, plasmids and constructs}

The yeast strain GG1259 (haploid leu2-3,112 ura3-52 trp192 bmh1::LEU2 bmh2::URA3 his4 pYES-TRP(GF14); a generous gift from Dr. G. P. H. van Heusden, Leiden University, The Netherlands) was used. The strain was modified by disrupting the URA cassette and selected by 5fluoroorotic acid, 5-FoA (Wako Pure Chemicals, Osaka, Japan), and used as a host for the transformation by pEVP11 plasmid [57] bearing either wild-type or mutant 14-3-3e cDNAs. pEVP1 1 contains the ADH promoter and has uracil as a selection maker. pYES(GF14) plasmid, initially present to rescue the $b m h 1-b m h 2$ double knockout, was shuffled from the cells. The resulting new strains expressing $14-3-3 \varepsilon$ or $14-3-3 \varepsilon-\alpha 5$ proteins were used as genetic backgrounds for the rest of the experiments. YPD and complete minimal dropout medium with a further addition of the specific nutrient requirement were used when mentioned. All cell cultures were grown at $30^{\circ} \mathrm{C}$.

\section{Test plasmids-pARS-I and pARS-2}

The episomal plasmid pRS313-HIS3 contains ARSH4 as a yeast origin of replication. It has been used without any modifications as test plasmid pARS-1, or modified by the insertion of ARS307 sequence to construct the test plasmid pARS-2. pARS-2 was constructed by cloning, in the pRS313 multiple cloning site, a 365 bp EcoRI-SalI ARS307 fragment which was initially amplified from the pRS306 plasmid bearing the ARS307 sequence (a gift from Dr. C S Newlon, Univ. of New Jersey Medical School). The PCR 
amplification of this fragment was done by using the PARS307 primers (Tab. 1). Successful cloning of the ARS307 fragment in pARS-2 was verified by sequencing.

\section{Deletion of the $\alpha 5$ domain in 14-3-3 epsilon protein}

Full-length human 14-3-3e cDNA (a gift from Dr. A. Aitken, Univ. of Edinburgh) was used as template DNA to construct the deleted protein. Deletion of the $\alpha-5$ helix of 14-3-3 $\varepsilon$ was produced by polymerase chain reaction (PCR) amplification of two fragments, both lacking the 60 bp sequence DNA of the $\alpha-5$ helix. The primers used to make this deletion are listed in Table 1. Both fragments were digested with StyI restriction enzyme, followed by ligation. Wild-type and mutant PCR products were cloned separately into plasmid pEVP11 and the corresponding DNA sequences were verified by sequencing. The resulting plasmids were then used to transform yeast GG1259 cells by the lithium acetate procedure.

\section{Whole cell extract and western blotting}

Cells were bead-beaten in lysis buffer $(50 \mathrm{mM}$ Tris, $\mathrm{pH}$ 7.5, 0.1\% Triton X-100, $100 \mathrm{mM} \mathrm{NaCl}, 2.0$ mM EDTA, 2.0 $\mathrm{mM}$ phenylmethylsulfonyl fluoride, $2.0 \mathrm{mM}$ Sodium orthovanadate (Na3VO4), and $20 \mathrm{mM}$ EGTA, $50 \mathrm{mM}$ $\mathrm{NaF}$ ), supplemented with 1 pill of protease inhibitors (Roche Molecular Biochemicals) before use. Lysate free of beads was microcentrifuged at maximum speed for $5 \mathrm{~min}$ utes at $4{ }^{\circ} \mathrm{C}$. The supernatant was mixed with equal volume of $2 \times$ protein sample buffer containing $100 \mathrm{mM}$ dithiothreitol, and the samples were loaded onto a $12 \%$ SDS-polyacrylamide gel. Electrophoresis was carried out at $120 \mathrm{~V}$ for 90 minutes, and the gel contents were subsequently transferred onto Immobilon ${ }^{\mathrm{TM}} \mathrm{P}$ transfer membrane. Immunoblotting was done by using anti-14-3-3e antibody (T16) (Santa Cruz Biotechnology), anti-Bmh1 antibody (a gift from Dr van Heusden, Netherlands), and anti-Ras2 antibody (yC-19) (Santa Cruz Biotechnology).

\section{Electromobility-shift assay}

\section{Band-shift assays}

Cruciform-containing DNA was constructed and endlabelled as described previously [7]. $20 \mu \mathrm{g}$ of wild-type or mutant whole cell extracts (WCE) were incubated with 3 ng of labelled cruciform DNA for 30 minutes on ice in binding buffer, as previously described [7]. The mixtures were subjected to $4 \%$ polyacrylamide gel electrophoresis (PAGE) at $180 \mathrm{~V}$ for $2 \mathrm{~h}$. The gel was dried and exposed for autoradiography. R18 experiment was done as described previously [38] prior to the mobility shift assay. $20 \mu \mathrm{g}$ of wild type $14-3-3 \varepsilon$ yeast extract was incubated without or with increasing amounts $(10,50$ and $100 \mu \mathrm{M})$ of R18 (Biomol International, LP) for 30 minutes at $30^{\circ} \mathrm{C}$. Cruciform binding assay reagents were added and incubated on ice for 30 minutes before loading on the gel as described above.

\section{Band-shift elution and immunoblotting}

Wild-type and $\alpha 5$-deleted $14-3-3 \varepsilon$ proteins were purified as previously described [8] with some modifications. In brief, $300 \mathrm{ng}$ of labelled cruciform DNA [7] was used for binding either wild-type or mutant $14-3-3 \varepsilon$ from $100 \mu \mathrm{g}$ of their respective WCEs. Cruciform-protein complexes were subjected to PAGE in a $4 \%$ polyacrylamide gel at 180 $\mathrm{V}$ for $1.5 \mathrm{~h}$. Each complex was eluted from the gel by isotachophoresis, as previously described [8]. Eluates were concentrated to $3 \mu \mathrm{g} / \mu \mathrm{l}$ with Microcon YM-10 concentrator (Millipore Corp.). Then, $30 \mu \mathrm{g}$ of each band shifteluted preparation were mixed with $1 \times$ SDS sample buffer containing $100 \mathrm{mM}$ dithiothreitol, and the samples were subjected to PAGE in a $12 \%$ SDS-polyacrylamide gel. The gel contents were transferred into Immobilon ${ }^{\mathrm{TM}} \mathrm{P}$ transfer membrane, which was probed with anti-14-3-3e antibody (T16) (Santa Cruz Biotechnology).

\section{Chromatin immunoprecipitation (ChIP) assay in vivo cross-linking}

In vivo cross-linking was carried out essentially as previously described [58]. In brief, $50 \mathrm{ml}$ of wild-type and mutant cells were grown in YPD to $A_{595}=0.8-1.0$. Cells were crosslinked with $1 \%$ formaldehyde and incubated for 1 hour at room temperature with gentle shaking. Cells were harvested by centrifugation at $1000 \times g$ at $4{ }^{\circ} \mathrm{C}$ for 15 minutes, the pellets were washed twice with ice-cold PBS, and then once with buffer I (50 mM Hepes/KOH $(\mathrm{pH}$ 7.5), $140 \mathrm{mM} \mathrm{NaCl}, 1 \mathrm{mM}$ EDTA (pH 7.5), 1\% (v/v) Triton $\mathrm{X}-100$, and $0.1 \%(\mathrm{w} / \mathrm{v})$ sodium deoxycholate).

\section{Preparation of whole cell extracts}

Pellets from cross-linked cells were resuspended in $250 \mu \mathrm{l}$ of ice-cold buffer I containing protease inhibitors ( $1 \mathrm{mM}$ phenylmethylsulfonyl fluoride and one tablet of protease inhibitors (Roche Molecular Biochemicals). The cell suspensions were lysed by bead-beating for 30 seconds and then chilled on ice for another 30 seconds for eight cycles. Beads were discarded and the lysates were sonicated for 15 seconds eight times, with 30 seconds intervals on ice between each pulse to chill the samples. After centrifugation at $14,000 \mathrm{rpm}$ for 15 minutes at $4{ }^{\circ} \mathrm{C}$, protein concentrations of all samples were normalized with ice-cold buffer I. An aliquot of this supernatant served as the whole cell extract (WCE).

\section{Immunoprecipitation and DNA isolation}

$2 \mathrm{mg}$ total proteins of the WCE was precleared with $50 \mu \mathrm{l}$ of protein G-agarose (Roche Molecular Biochemicals) for $1 \mathrm{~h}$ at $4^{\circ} \mathrm{C}$ and then incubated at $4^{\circ} \mathrm{C}$ for $12 \mathrm{~h}$ with $10 \mu \mathrm{l}$ of either preimmune serum or $5 \mu \mathrm{g}$ of anti-14-3-3e antibody (Santa Cruz biotechnology). $50 \mu$ l of protein G-agarose was added, and the incubation was continued for 2 h. The precipitates were successively washed twice for 5 minutes at $4^{\circ} \mathrm{C}$ with $1 \mathrm{ml}$ of each of the following buffers: 
ice-cold buffer I, ice-cold buffer II (50 mM Hepes/KOH (pH 7.5), 500 mM NaCl, 1 mM EDTA (pH 7.5), 1\% (v/v) Triton $\mathrm{X}-100$, and $1 \%(\mathrm{w} / \mathrm{v})$ sodium deoxycholate); icecold buffer III (10 mM Tris-Cl (pH 8.0), $250 \mathrm{mM} \mathrm{LiCl,} 1$ mM EDTA (pH 7.5), 0.5\% (v/v) Nonidet P-40, and 0.5\% $(\mathrm{w} / \mathrm{v})$ sodium deoxycholate); and ice-cold Tris/EDTA buffer ( $\mathrm{pH}$ 7.6). Finally, the pellets were resuspended in $200 \mu \mathrm{l}$ of extraction buffer (1\% SDS/Tris/EDTA buffer). Samples were then incubated at $65^{\circ} \mathrm{C}$ overnight to reverse the protein-DNA cross-links, followed by $2 \mathrm{~h}$ incubation at $37^{\circ} \mathrm{C}$ with $50 \mu \mathrm{g}$ of proteinase $\mathrm{K}$ (Roche Molecular Biochemicals). At the end, samples were processed to purify the DNA by passing them through QIAquick PCR purification columns (QIAGEN Inc., Valencia, CA).

\section{PCR amplification of the co-immunoprecipitated DNA}

The immunoprecipitated materials, WCE and genomic DNA, were used as templates in conventional PCR with Ready-To-Go PCR beads (Amersham Biosciences). Primers ARS307 ( $1 \mu \mathrm{M}$ each; GENSETCorp.) (Tab. 1) were used to amplify a 370-bp DNA fragment from the yeast autonomous replication sequence ARS307 (GenBank ${ }^{\mathrm{TM}}$ ) EBI accession number X04219). An initial denaturation for 5 minutes at $94^{\circ} \mathrm{C}$ was followed by 35 cycles of denaturing for 30 seconds at $94^{\circ} \mathrm{C}$, annealing for 30 seconds at $50^{\circ} \mathrm{C}$, polymerization for 1 minute at $72^{\circ} \mathrm{C}$, and a final extension for 10 minutes at $72^{\circ} \mathrm{C}$. PCR products were separated on $1.5 \%$ agarose gel, visualized with ethidium bromide, and photographed with an Eagle Eye apparatus (Speed Light/BT Sciencetech-LT1000).

Real-time PCR amplification of the co-immunoprecipitated DNA PCR reactions were carried out in $20 \mu \mathrm{l}$ with one-two hundredth of the immunoprecipitated material, using LightCycler capillaries (Roche Molecular Biochemicals). Specific primers for the Real-time PCR (listed in Table 1) were added at $1 \mu \mathrm{M}$ concentration. Genomic DNA was used to generate the standard curve. For the Real-time PCR reactions, an initial denaturation for 5 minutes at $95^{\circ} \mathrm{C}$ was followed by 35 cycles with denaturation for $15 \mathrm{sec}-$ onds at $95^{\circ} \mathrm{C}$; the annealing temperatures were used according to different fragments amplified (ARS307, Neg307, ARS1 or R2.5) for 10 seconds, followed by polymerization for 10 seconds at $72{ }^{\circ} \mathrm{C}$. The specificity of the amplified PCR products was assessed by performing a melting curve analysis after the PCR amplification.

\section{Plasmid stability assay}

The assay was performed as described [59]. pARS-1 and pARS-2 were used separately to transform both wild type and mutant $14-3-3 \varepsilon$ yeast strains, using the standard lithium acetate method. Cells were then grown to early logphase in selective medium, SCM-His. The cultures were diluted to $210^{5}$ cells $/ \mathrm{ml}$ in YPD and grown for 10 generations. Equal amounts of cells were then plated on YPD and SCM-His plates, and plasmid loss rates were determined by counting colonies before and after incubation in YPD media. The stability value for each plasmid is an average of three independent experiments, each using colonies from a separate transformation.

\section{List of abbreviations}

ACS, ARS consensus sequence; ARS, autonomous replication sequence; CBP, cruciform-specific binding protein; ChIP, chromatin immunoprecipitation; IR, inverted repeat; ORC, origin recognition complex; pre-RC, prereplication complex; ts, temperature sensitive mutant; WCE, whole cell extract.

\section{Authors' contributions}

WY carried out all the experiments described in the study except for the Uracil disruption cassette in GG1259 cells and the deletion of $\alpha 5$-helix in $14-3-3 \varepsilon$ protein, and also conceived and designed the study and wrote the manuscript. MC carried out the GG1259 uracil cassette disruption and the $\alpha 5$-helix deletion in $14-3-3 \varepsilon$ protein, and helped to conceive the study. GBP initially supervised and helped to conceive the study. MZH supervised the study and the manuscript. All authors, except GBP, have read and approved the final manuscript.

\section{Acknowledgements}

This work was supported by a grant from the Cancer Research Society and the Canadian Institute of Health Research (MOP 69029). WY was a recipient of a doctoral studentship from ClHR/Cancer Consortium Training Research.

\section{References}

I. Zannis-Hadjopoulos M, Frappier L, Khoury M, Price GB: Effect of anti-cruciform DNA monoclonal antibodies on DNA replication. EMBO J 1988, 7:1837-1844.

2. Pearson CE, Zorbas H, Price GB, Zannis-Hadjopoulos M: Inverted repeats, stem-loops, and cruciforms: Significance for initiation of DNA replication. J Cell Biochem 1996, 63: I-22.

3. Ward GK, Shihab-El-Deen A, Zannis-Hadjopoulos M, Price GB: DNA cruciforms and the nuclear supporting structure. Exp Cell Res 1991, 195:92-98.

4. Callejo M, Alvarez D, Price GB, Zannis-Hadjopoulos M: The 14-3-3 protein homologues from Saccharomyces cerevisiae, Bmhlp and Bmh2p, have cruciform DNA-binding activity and associate in vivo with ARS307. J Biol Chem 2002, 277:38416-38423.

5. Frappier L, Price GB, Martin RG, Zannis-Hadjopoulos M: Monoclonal antibodies to cruciform DNA structures. J Mol Biol 1987, 193:75I-758.

6. Frappier L, Price GB, Martin RG, Zannis-Hadjopoulos M: Characterization of the binding specificity of two anticruciform DNA monoclonal antibodies. I Biol Chem 1989, 264:334-34I.

7. Pearson CE, Ruiz M, Price GB, Zannis-Hadjopoulos M: Cruciform DNA binding protein in HeLa cell extracts. Biochemistry 1994, 33:14|85-14196.

8. Todd A, Cossons N, Aitken A, Price GB, Zannis-Hadjopoulos M: Human cruciform binding protein belongs to the 14-3-3 family. Biochemistry 1998, 37: 14317-I4325.

9. Rosenquist M, Sehnke P, Ferl RJ, Sommarin M, Larsson C: Evolution of the 14-3-3 protein family: does the large number of isoforms in multicellular organisms reflect functional specificity? [In Process Citation]. J Mol Evol 2000, 5 I:446-458.

10. Aitken A: Functional specificity in 14-3-3 isoform interactions through dimer formation and phosphorylation. Chromo- 
some location of mammalian isoforms and variants. Plant $\mathrm{Mol}$ Biol 2002, 50:993-1010.

II. Zannis-Hadjopoulos M, Novac O, Alvarez D, Price GB: 14-3-3s are DNA-replication proteins. Biochem Soc Trans 2002, 30:397-40I.

12. Hermeking H: 14-3-3 proteins and cancer biology. Semin Cancer Biol 2006, 16:161.

13. Pearson CE, Zannis-Hadjopoulos M, Price GB, Zorbas H: A novel type of interaction between cruciform DNA and a cruciform binding protein from HeLa cells. EMBO J 1995, | 4: I57|-| 580.

14. Xiao B, Smerdon S], Jones DH, Dodson GG, Soneji Y, Aitken A, Gamblin SJ: Structure of a 14-3-3 protein and implications for coordination of multiple signalling pathways. Nature 1995 , 376: $|88-19|$.

15. Petosa C, Masters SC, Bankston LA, Pohl J, Wang BC, Fu HI, Liddington RC: I 4-3-3zeta binds a phosphorylated Raf peptide and an unphosphorylated peptide via its conserved amphipathic groove. J Biol Chem I998, 273(26): I6305-10.

16. Steinmetzer K, Zannis-Hadjopoulos M, Price GB: Anti-cruciform monoclonal antibody and cruciform DNA interaction. J Mol Biol 1995, 254:29-37.

17. Yaffe MB, Rittinger K, Volinia S, Caron PR, Aitken A, Leffers H, Gamblin SJ, Smerdon SJ, Cantley LC: The structural basis for I4-33:phosphopeptide binding specificity. Cell 1997, 91:961-971.

18. Alvarez D, Novac O, Callejo M, Ruiz MT, Price GB, Zannis-Hadjopoulos $M$ : 14-3-3 sigma is a cruciform DNA binding protein and associates in vivo with origins of DNA replication. I Cell Biochem 2002, 87: 194-207.

19. Novac O, Alvarez D, Pearson CE, Price GB, Zannis-Hadjopoulos M The human cruciform-binding protein, CBP, is involved in DNA replication and associates in vivo with mammalian replication origins. J Biol Chem 2002, 277( I 3): I I I74-83.

20. Pozuelo Rubio M, Geraghty KM, Wong BH, Wood NT, Campbell DG, Morrice N, Mackintosh C: 14-3-3-affinity purification of over 200 human phosphoproteins reveals new links to regulation of cellular metabolism, proliferation and trafficking. Biochem J 2004, 379:395-408.

21. Meek SE, Lane WS, Piwnica-Worms H: Comprehensive proteomic analysis of interphase and mitotic 14-3-3-binding proteins. J Biol Chem 2004, 279:32046-32054.

22. Satoh J, Nanri Y, Yamamura T: Rapid identification of 14-3-3binding proteins by protein microarray analysis. J Neurosci Methods 2006, I 52:278-288.

23. Dalal SN, Yaffe MB, DeCaprio JA: 14-3-3 family members act coordinately to regulate mitotic progression. Cell Cycle 2004, 3:672-677.

24. Fujita N, Sato S, Katayama K, Tsuruo T: Akt-dependent phosphorylation of p27Kip I promotes binding to I 4-3-3 and cytoplasmic localization. J Biol Chem 2002, 277(32):28706-I3.

25. Sekimoto $T$, Fukumoto $M$, Yoneda $Y$ : I 4-3-3 suppresses the nuclear localization of threonine I57-phosphorylated p27(Kip I). Embo J 2004, 23: 1934- 1942.

26. Nguyen A, Rothman DM, Stehn J, Imperiali B, Yaffe MB: Caged phosphopeptides reveal a temporal role for I4-3-3 in G I arrest and S-phase checkpoint function. Nat Biotechnol 2004, 22:993-1000.

27. van Heusden GP, Wenzel T], Lagendijk EL, de Steensma HY, van den Berg JA: Characterization of the yeast BMHI gene encoding aputative protein homologous to mammalian protein kinase II activators and protein kinase $\mathbf{C}$ inhibitors. FEBS Lett 1992 , 302: $145-150$.

28. van Hemert MJ, van Heusden GP, Steensma HY: Yeast I 4-3-3 proteins. Yeast 200I, 18:889-895.

29. Lottersberger F, Panza A, Lucchini G, Piatti S, Longhese MP: The Saccharomyces cerevisiae 14-3-3 proteins are required for the $\mathbf{G}$ I/S transition, actin cytoskeleton organization and cell wall integrity. Genetics 2006.

30. Bell SP, Dutta A: DNA replication in eukaryotic cells. Annu Rev Biochem 2002, 7 I:333-374.

31. Van Heusden GPH, Griffiths DJF, Ford JC, Chin-A-Woeng TFC, Schrader PAT, Carr AM, Steensma HY: The 14-3-3 proteins encoded by the $B M H I$ and $B M H 2$ genes are essential in the yeast Saccharomyces cerevisiae and can be replaced by a plant homologue. Eur J Biochem 1995, 229:45-53.

32. Van Heusden GPH, Van der Zanden AL, Ferl RJ, Steensma HY: Four Arabidopsis thaliana I4-3-3 protein isoforms can complement the lethal yeast $\mathrm{BMHI} B \mathrm{BH} 2$ double disruption. FEBS Lett 1996, 391:252-256.

33. Bruckmann A, Steensma HY, Teixeira De Mattos MJ, Van Heusden GP: Regulation of transcription by Saccharomyces cerevisiae I 4-3-3 proteins. Biochem J 2004, 382:867-875.

34. Sehnke PC, Henry R, Cline K, Ferl RJ: Interaction of a plant I4-33 protein with the signal peptide of a thylakoid-targeted chloroplast precursor protein and the presence of 14-3-3 isoforms in the chloroplast stroma. Plant Physiol 2000, I 22:235-242.

35. Furuse $M$, Nagase $Y$, Tsubouchi $H$, Murakami-Murofushi K, Shibata T, Ohta K: Distinct roles of two separable in vitro activities of yeast Mre I I in mitotic and meiotic recombination. Embo J 1998, I 7:6412-6425.

36. Rass U, Kemper B: Crplp, A New Cruciform DNA-binding Protein in the Yeast Saccharomyces cerevisiae. I Mol Biol 2002, 323:685-700.

37. Wang B, Yang H, Liu YC, Jelinek T, Zhang L, Ruoslahti E, Fu H: Isolation of high- affinity peptide antagonists of I 4-3-3 proteins by phage display. Biochemistry 1999, 38: I 2499- I 2504.

38. Chiang CW, Kanies C, Kim KW, Fang WB, Parkhurst C, Xie M, Henry T, Yang E: Protein phosphatase 2A dephosphorylation of phosphoserine I I 2 plays the gatekeeper role for BAD-mediated apoptosis. Mol Cell Biol 2003, 23:6350-6362

39. Roberts RL, Mosch HU, Fink GR: I 4-3-3 proteins are essential for RAS/MAPK cascade signaling during pseudohyphal development in S. cerevisiae. Cell 1997, 89: I055-1065.

40. Rao H, Marahrens Y, Stillman B: Functional conservation of multiple elements in yeast chromosomal replicators. Mol Cell Biol 1994, | 4:7643-765I.

4I. Theis JF, Newlon CS: Domain B of ARS307 contains two functional elements and contributes to chromosomal replication origin function. Mol Cell Biol 1994, I4:7652-7659.

42. Hogan E, Koshland D: Addition of extra origins of replication to a minichromosome suppresses its mitotic loss in cdc6 and cdc 14 mutants of Saccharomyces cerevisiae. Proc Natl Acad Sci USA 1992, 89:3098-3102.

43. Zou L, Mitchell J, Stillman B: CDC45, a novel yeast gene that functions with the origin recognition complex and MCM proteins in initiation of DNA replication. Mol Cell Biol 1997, 1 7:553-563.

44. Alvarez D, Callejo M, Shoucri R, Boyer L, Price GB, Zannis-Hadjopoulos $M$ : Analysis of the cruciform binding activity of recombinant I4-3-3zeta-MBP fusion protein, its heterodimerization profile with endogenous 14-3-3 isoforms, and effect on mammalian DNA replication in vitro. Biochemistry 2003, 42:7205-7215.

45. Aitken A, Baxter H, Dubois T, Clokie S, Mackie S, Mitchell K, Peden A, Zemlickova E: Specificity of 14-3-3 isoform dimer interactions and phosphorylation. Biochem Soc Trans 2002, 30:35I-360.

46. Chaudhri M, Scarabel M, Aitken A: Mammalian and yeast 14-3-3 isoforms form distinct patterns of dimers in vivo. Biochem Biophys Res Commun 2003, 300:679-685.

47. Deshpande AM, Newlon CS: The ARS consensus sequence is required for chromosomal origin function in Saccharomyces cerevisiae. Mol Cell Biol 1992, I 2:4305-43 I3.

48. Bell SP, Stillman B: ATP-dependent recognition of eukaryotic recognition of origins of DNA replication by multiprotein complex. Nature 1992, 357:। 28-I34.

49. Diffley JFX, Cocker JH, Dowell SJ, Rowley A: Two steps in the assembly of complexes at yeast replication origins in vivo. Cell 1994, 78:303-316.

50. Diffley JFX, Cocker JH: Protein-DNA interactions at a yeast replication origin. Nature 1992, 357:169-172.

5I. Bell SP, Mitchell J, Leber J, Kobayashi R, Stillman B: The multidomain structure of Orclp reveals similarity to regulators of DNA replication and transcriptional silencing. Cell 1995 , 83:563-568

52. Gavin KA, Hidaka M, Stillman B: Conserved initiator proteins in eukaryotes. Science 1995, 270:1667-167I.

53. Gerbi SA, Strezoska Z, Waggener JM: Initiation of DNA replication in multicellular eukaryotes. I Struct Biol 2002, I40: I7-30.

54. Ruiz MT, Matheos D, Price GB, Zannis-Hadjopoulos M: OBA/Ku86: DNA binding specificity and involvement in mammalian DNA replication. Mol Biol Cell 1999, I 0:567-580.

55. Macdonald N, Welburn JP, Noble ME, Nguyen A, Yaffe MB, Clynes D, Moggs JG, Orphanides G, Thomson S, Edmunds JW, et al.: Molecular 
basis for the recognition of phosphorylated and phosphoacetylated histone $\mathrm{h} 3$ by 14-3-3. Mol Cell 2005, 20: 199-2II.

56. Gambus A, Jones RC, Sanchez-Diaz A, Kanemaki M, van Deursen F, Edmondson RD, Labib K: GINS maintains association of Cdc45 with MCM in replisome progression complexes at eukaryotic DNA replication forks. Nat Cell Biol 2006, 8:358-366.

57. Russel P: Gene cloning and expression in fission yeast. In Molecular Biology of the Fission Yeast Edited by: Nasim A, Young P and Johnson PF. Academic Press, San Diego, CA; 1989:244-272.

58. Takahashi K, Saitoh S, Yanagida M: Application of the chromatin immunoprecipitation method to identify in vivo proteinDNA associations in fission yeast. Sci STKE 2000, 2000:PLI.

59. Yan H, Gibson S, Tye BK: $\mathbf{M c m} 2$ and $M \mathrm{~cm}^{3}$, two proteins important for ARS activity, are related in structure and function. Genes Dev 199I, 5:944-957.

Publish with Bio Med Central and every scientist can read your work free of charge

"BioMed Central will be the most significant development for disseminating the results of biomedical research in our lifetime. "

Sir Paul Nurse, Cancer Research UK

Your research papers will be:

- available free of charge to the entire biomedical community

- peer reviewed and published immediately upon acceptance

- cited in PubMed and archived on PubMed Central

- yours - you keep the copyright

Submit your manuscript here:

http://www.biomedcentral.com/info/publishing_adv.asp
BiolMedcentral 